www.jmscr.igmpublication.org

Index Copernicus Value: 79.54

ISSN (e)-2347-176x ISSN (p) 2455-0450

crossref DOI: https://dx.doi.org/10.18535/jmscr/v7i5.72

\title{
To compare the study of audio visual reaction time before and after pranayama training: A prospective observational study
}

\author{
Authors \\ Dr Rajkumar ${ }^{1}$, Dr Anita Moral ${ }^{2}$ \\ ${ }^{1}$ Assistant Professor, Department of Physiology, Mulayam Singh Yadav Medical College, Meerut \\ ${ }^{2}$ Assistant Professor, Department of Psychology, S V Degree College, Aligarh \\ Corresponding Author
}

Dr Anita Moral

Assistant Professor, Department of Psychology, S V Degree College, Aligarh, India

\begin{abstract}
Background: Yoga enhances physical and emotional health and increases the performance of personnel. The aim of this study was undertaken to see the effect of Pranayama on Visual reaction time (VRT) and Audio-reaction time (ART).

Material \& Methods: This is a prospective observational study done on 50 Medical and Paramedical students of Mulayam Singh Yadav Medical College Meerut. Pranayama training was given to all subjects daily six days a week for one month. All subjects were undergoes audio reaction time, visual reaction time before pranayama training and after duration of pranayama training.

Results: Our study showed that the difference of mean value of audio reaction time \& visual reaction time in between pre-yoga \& post-yoga was statistical significant $(P<0.0001 * * *$ each $)$

Conclusion: We suggest that regular practice of pranayam improves reaction time and higher brain functions.

Keywords: Audio reaction time, Visual reaction time, Medical students, Pranayam.
\end{abstract}

\section{Introduction}

Human race has travelled millions of miles in the roads of industrialization and modernization. Mankind has gone so far along with modern gadgets which had made our lives indescribably comfortable. Rapid alterations of life style within a very short span of time leads to chronic imbalance in both body and mind impending a direct effect on the physiology of mankind.

Since centuries many sages \& rishis have recommended the practice of yoga, meditation \& pranayama to prevent or minimize our reaction to stress. Yoga enhances physical and emotional health and increases the performance of personnel. Shortening of audio-visual reaction time after pranayam training signifies greater arousal, improved concentration \& faster responsiveness. ${ }^{1}$

Yoga is an ancient science \& an art of exercise which is associated with a set of principles \& practices which are designed to promote the health $\&$ the well being through the integration of the body, breath \& the mind. Its components include Aasnas (postures), pranayama (voluntary breath regulation \& dhyana) (meditation). Yoga is 
commonly called as a mind-body therapy \& it has often been claimed that it can enhance one's ability to focus the attention, improve the cognitive abilities, decrease the stress \& increase $\&$ improve the organ system's strength suppleness CNS. It has been reported that yoga training improves the human performance, which includes the CNS processing. ${ }^{2}$

Definition of Pranayama in Yogasutras of Patanjali is regulation of incoming and outgoing breath with retention which follows after securing steadiness of posture. ${ }^{3}$ Breath control techniques are said to affect the higher functions of CNS like perception, planning, learning and memory. The study of reaction time spuns more than a century and provides an indirect index of the processing capability of the central nervous system and also a simple means of determining sensorimotor performance. $^{4}$

Human body responses to a number of external environmental stimuli of different modalities and gives a desired, purposeful voluntary response to different types of stimuli. Human reaction time (RT) is the time interval between the application of a stimulus and the appearance of appropriate voluntary response by a subject. ${ }^{5}$

Audio-visual reaction time is the index of the processing ability of the central nervous system. This test has physiological as well as clinical significance, which is a prerequisite for sports, precision surgeons \& other professionals too. ${ }^{6}$

Pranayamic practitioners are known to have better attention and less distractibility. It has been reported that this form of yoga practice results in a decreased in mental fatigability and an increase in performance quotient. Since performance of an athlete is directly linked with duration of reaction time, determination of reaction time could be used to screen a large population for physical fitness. Thus determination of reaction time has important implications in sports physiology. ${ }^{7}$

Many factors have been shown to affect reaction time including, age, gender, physical fitness, fatigue, fasting, distraction, alcohol, breathing cycle, personality type, exercise, intelligence of the subject and whether the stimulus is auditory or visual. Out of these various factors, the present study was undertaken to see the effect of Pranayama on Visual reaction time (VRT) and Audio-reaction time (ART).

\section{Material \& Methods}

This is a prospective observational study done on 50 Medical and Paramedical students of Mulayam Singh Yadav Medical College Meerut.

\section{Inclusion Criteria}

1. Healthy Medical and paramedical students aged to $18-25$ years

2. Willingness to participate.

\section{Exclusion Criteria}

1. Students with history of any neurologic, psychiatric, cardiovascular, respiratory or systemic illness, smokers and alcoholic were excluded.

2. Students on psychotic drugs, antihistaminics and epileptics were excluded from study.

3. Those who are already practicing Pranayam or exercise were not included in this study.

\section{The Preparation for Pranayama}

1) Subjects were asked to come with empty stomach and empty bladder after taking a bath.

2) The timing for pranayama practice was fixed in early morning before sunrise.

3) The place of practice of pranayama was the common room of the hostel.

4) Subjects were asked to practice pranayama while sitting on the floor on a carpet.

5) The subjects were asked to take a proper sitting position either in Padmasana (the lotus posture) or Sukhasana (the comfortable posture) or Vajrasana (the thunder bolt posture).

6) After the subjects had assumed the proper posture, they were instructed to close their eyes and concentrate on the sound of breathing.

7) They were then asked to inhale slowly and deeply followed by pronounciation of 
'OM' (A---------U--------M) during slow and gentle exhalation. Three such pronounciation of ' $\mathrm{OM}$ ' were performed before starting the pranayama.

\section{Procedure $^{3}$}

Pranayama training was given to all subjects daily six days a week for one month. They was given pranayama training by a qualified yoga teacher. Following pranayama techniques was daily practiced for 40 minutes.

1. Kapalbhati Pranayama: Kapalbhati pranayama involves a vigorous expiration with a slow, passive inspiration.

A) During each exhalation, subject forcefully blasted air out by vigorous inward sucking movement of the abdomen.

B) Then slow and gentle inhalation was done passively by relaxing the abdominal muscles.

C) After the end of practice; an autonomic suspension of breath was observed. Infact there was no urge for breathing for a few seconds.

2. Deergh swas Pranayama : 5 minute

(Slow and deep inspiration through nostrils and slowly expiration through mouth. The ratio of inspiration:expiration time is $1: 2$.) (1 minute interval)

3. Anulom-Vilom Pranayama: Alternate nostril breathing, where in nostril is changed with each inspiration.

A) The right nostril was closed with the right thumb and inhalation was done slowly and deeply through the left nostril by the subjects.

B) The left nostril was closed with the ring and little finger and the right nostril was released, exhalation was done slowly and completely through the right nostril.

C) Inhalation was done slowly and deeply through the same (right) nostril, keeping the left nostril closed and then the right nostril was closed and exhalation was done slowly and completely through the left nostril.

Yhe above completed one cycle of anulom-vilom pranayama.

4. Bhramari Pranayama: 'Bhramar' means a large black bumble bee and this pranayama is so called because during exhalation a soft humming sound like that of a bumble bee is made.

A) The subjects, after a deep inhalation, exhaled very slowly with a humming sound.

B) Bhramari pranayama was done while performing Sunmukhi Mudra. (1 minute interval)

Sunmukhi Mudra.

C) The subjects were asked to raise the hands to the face and the elbows to the level of the shoulders.

D) They were instructed to place the thumb tips in the external auditory meatus to keep out external sounds.

E) They were asked to close the eyes and cover the eyelids with the fore and middle fingers. The upper eyelids were drawn down with the pad of the middle fingertips and the fore fingertips to keep out the light. The eye balls were kept gently pressed with the fingers.

F) The nostrils were kept pressed with the ring fingertips to narrow the nasal passage for slow, steady, rhythmic and subtle breathing. The little fingers were kept on the upper lip to feel the flow of breath.

5. Omkar Chanting: After completing the pranayama practice, three pronounciations of 'OM' were performed 3 times in 3 minutes at one minute interval.

6. Meditation: 15 minutes (Concentration on own breathing and chest movements)

One minute interval was compulsory before next step performance pranayama.

All subjects were undergoes audio reaction time, visual reaction time before pranayama training 
and after duration of pranayama training. Test was performed between 9:00 a.m to 11:00 ${ }^{\circ}$ clock A.m. at a comfortable room temperature $25-30^{\circ} \mathrm{C}$ in noise free room.

Prior to recruitment in the study, a written informed consent was obtained from each subject, indicating their voluntary participation in the study. The consent form was explained the purpose of study and an assurance regarding confidentiality of the subject's identity. Also a declaration that information so collected as a part of the study. The participants were free to raise queries on any aspect of the study, their participation and its implications thereof. Also the participants were expressed their right to opt out of the study at any stage without giving an explanation for the same..

\section{Reaction Time}

The apparatus used to measure reaction time is 'Research reaction time apparatus' (Yantrashilp) manufactured by Anand agencies, Pune-2. It is a portable device within built four digit chronoscope with least count of 1/1000 sec. i.e. 1 millisecond. Green light stimuli and high frequency beep stimuli was selected for recording visual reaction time and auditory reaction time respectively. Once the subject got familiarized with the instrument, the final reading was taken. ${ }^{8}$ For auditory reaction time three reading of the high frequency beep stimuli was recorded. ${ }^{9}$

For visual reaction time three readings of the green light stimulus was recorded in milliseconds from auto display. The average of three readings was taken. ${ }^{8}$ As soon as the stimulus is perceived by the subjects, he/she were asked to responds by pressing there response switch by index finger of the dominant and for each subject the lowest reading was taken as the value for the reaction time task.

\section{Results}

Our study showed that the difference of mean value of audio reaction time $\&$ visual reaction time in between pre-yoga \& post-yoga was statistical significant $\left(\mathrm{P}<0.0001^{* * *}\right.$ each) (table 1 \& 2).

Table 1: Effect of Pranayam on audio reaction time

\begin{tabular}{|l|c|c|c|c|c|}
\hline Group & $\mathrm{N}$ & $\begin{array}{c}\text { Mean } \\
(\text { Sec.) }\end{array}$ & \pm SD & t-test & P-value \\
\hline Pre yoga & 50 & 0.1653 & 0.01632 & 23.07 & $<0.0001 * * *$ \\
\cline { 1 - 5 } Post yoga & 50 & 0.1197 & 0.01618 & & \\
\hline
\end{tabular}

Table 2: Effect of Pranayam on visual reaction time

\begin{tabular}{|l|c|c|c|c|c|}
\hline Group & $\mathrm{N}$ & $\begin{array}{c}\text { Mean } \\
(\text { Sec. })\end{array}$ & $\pm S D$ & t-test & P-value \\
\cline { 1 - 4 } Pre yoga & 50 & 0.1982 & 0.01375 & 26.21 & $<0.0001 * * *$ \\
\cline { 1 - 5 } Post yoga & 50 & 0.1376 & 0.01517 & & \\
\hline
\end{tabular}

\section{Discussion}

Yoga is commonly called as a mind-body therapy $\&$ it has often been claimed that it can enhance one's ability to focus the attention, improve the cognitive abilities, decrease the stress $\&$ increase $\&$ improve the organ system's strength suppleness CNS. Pranayama is an art and has technique to make the respiratory organs to move and expand intentionally, rhymically and intensively.

Medical students undergo tremendous stress during various stages of the MBBS course. Time is required for adjustment in new environment of college. Apart from these day to day problems, the students have a vast syllabus of $1^{\text {st }}$ M.B.B.S. The time they get for reading, understanding \& analyzing the three subjects were very less and associated they are under the other stressful conditions. To cope with these situations and excel in their curriculum further adds on to the stress which may lead to the decrease in the concentration, memory and remembering ability of the individual. Yoga and pranayama acts as an adjuvant and is useful for the disciplining of the mind for concentration.

Our study showed that the mean value of Audio reaction time in the medical and para- medical students before pranayama training \& after pranayama training which was found to be statistically highly significant. Similar results are reported by Madanmohan et al (1992) ${ }^{\mathbf{1 0}}$ who 
found that showed significant reduction in visual and auditory Reaction times in yoga training on twenty seven student volunteers for 12 weeks. A.S. Borkar, J.R. Pendekar $(\mathbf{2 0 0 3})^{7}$ found that there was reduction in ART from 0.188 to 0.139 sec. after 4 weeks of pranayamic breathing exercise, which is similar to our findings.

Dr. S.B. Jore et al $(\mathbf{2 0 1 3})^{11}$ found that after Pranayama training there was statistically significant decline in auditory reaction time. Another study done by Manish Dhadse, Ameet Fadia (2016) ${ }^{\mathbf{1 2}}$ observed to reduce auditory reaction time have health promoting, toning effects on central neural structures; quantity, pattern of release of neurotransmitters and mental interaction involved in information processing.

Effect of pranayama on reaction time could be due to greater cortical arousal \& faster rate of information processing, improved concentration power, ability to ignore external stimuli i.e. less distractibility and improved memory. ${ }^{13}$ The stress can cause affecting locomotor activity and altered behavioral changes (emotions and anxiety). ${ }^{14}$

\section{Conclusion}

We suggest that regular practice of pranayam improves reaction time and higher brain functions. Hence the best effects of these techniques would be evident if coupled as alternative therapy or as adjunct to conventional therapy in stress related disorders.

\section{References}

1. Malathi A, Parulkar VG. Effect of yogasanas on the visual and auditory reaction time. Indian $\mathrm{J}$ Physiol Pharmacol 1989; 33: 110-112.

2. Jansi R. N. Effect of enhancement of oxygen supply through yogic procedure on cognitive task performance. Journal of Indian psychology . 2006;24:1-6.

3. Maharshi Patanjali Krit Yog Darshan 2/49 ;97.

4. JOY: The journal of Yoga; Oct 2003; vol.2 no. 10 .
5. Misra N, Mahajan KK, Maini BK. Comparative study of visual and auditory reaction time of hands and feet in males and females. Indian J Physiol Pharmacol. 1985;29(4):213-8.

6. Liden DE. What, when, where in the Brain ? Exploring mental chronometry with brain imaging \& electrophysiology Rev Neuroscience. 2007 ; 18(2) ; 159-71.

7. A. S. Borker And J. R. Pednekar. Effect Of Pranayam On Visual And Auditory Reaction Time. Indian J Physiol Pharmacol 2003; 47 (2) : 229-230.

8. Mishra NV, Sonwane TD. A comparative study of Audio-Visual Reaction Time in Anemic and Non-Anemic Adolescent Girls. IJBAP, 2012; Vol. 1 (1): 79.

9. Vedavati $\mathrm{Kj}$ et al. Reaction time study as a tool to identify central nervous system affect due to hypothyroidism. IJSHR, 2013; 3(5):29-32.

10. Madanmohan, Thombre D. P. Balakumar b. et al . Effect of yoga training on reaction time respiratory endurance \& muscle strength. Indian journal physiology \& pharmacology 1992 ;36(4) 229-33.

11. Dr. S.B. Jore, Dr. Prathamesh Kamble , Dr. T.B. Bhutada, Dr. M.S. Patwardhan. Effect of Pranayama training on AudioVisual Reaction Time. International J. of Healthcare \& Biomedical Research, October 2013; Volume : 2, Issue:1: Pages 35-37.

12. Manish Dhadse, Ameet Fadia. Effect of Anulom Vilom Pranayam on auditory reaction time in Indian population aged 18-22 years. Int J Res Med Sci. 2016 Mar;4(3):891-895.

13. Raju PS, Madhavi S, Prasad KV, Reddy MV, Reddy ME, Sahay BK, Murthy KJ. Comparison of effects of yoga \& physical exercise in athletes. Indian $\mathbf{J}$ Med Res. 1994; 100:81-6.

14. Ambareesha Kondam, G. Purushothaman, Qairunnisa S, B.A. Madhuri, 
Sundararavadivel , V. P, G. Gajalakshmi, M. Chandrashekar, Effect of Subacute

Restraint Stress on mice in various

Neurobehavioral Parameters, Indian

Journal of Basic \& Applied Medical

Research; September 2013: Issue-8, Vol.-

2, P. 859-864. 